\title{
Study on Animal Environmental Welfare in the Intensive Livestock and Poultry Farms \\ ${ }^{1}$ Guiqin Li, ${ }^{1}$ Yanhong Geng, ${ }^{2}$ Hongmei Pang \\ ${ }^{1}$ Binzhou Polytechnic of Shandong Province in China \\ ${ }^{2}$ Binzhou Medical College in China \\ Wf-lgq@163.com , Yanhong Geng@163.com
}

Keywords: Environmental welfare, Intensive breeding, Livestock and Poultry.

\begin{abstract}
Under the conditions of intensive breeding, animal environmental welfare are not guaranteed, which will affect animals' health and the quality of animal products. Therefore, to effectively ensure the quality and safety of animal products, we should improve environmental welfare from microbial aerosols, ground and bedding materials, lighting, ventilation, ammonia consistence, temperature, density, noise etc.

In the 1960 s to 1970 s, People began to pay attention to the animal welfare in intensive breeding, after livestock and poultry husbandry changed from extensive range to intensive animal husbandry.[1] People observe that the conditions of the animal welfare directly affect the productivity. Hence, it's crucial to take some management measures, especially attaching great importance to the research of animal feed, enhancing nutrition such as the improvement the feed industry level, the development of complete feed, and reducing the morbidity and mortality by targeted animal immunization, which realize the aim of enhancing economic efficiency to certain extent.[2] But generally speaking, animals' living environment, quality of life and behavior need are far from satisfied, and animal welfare haven't been improved fundamentally. Under the conditions of intensive livestock and poultry breeding, animal welfare are not guaranteed, which will affect the quality of the animals and animal products.[3] Therefore, in order to effectively ensure the high quality and safety of animal products, it is necessary to take measures to improve animal environmental welfare.
\end{abstract}

\section{Microbial aerosol}

In intensive livestock and poultry breeding, amounts of dust discharged form farms carry large quantities and varieties of microbes, and provide nutrition and asylum for microorganisms, which greatly increase the microbial activity and prolong the survival time. The dust and microorganism can spread more than $30 \mathrm{~km}$ with the wind, thus expanding the scope of the pollution and harm. Dust pollution increase the inhalable particles in the atmosphere, worsen the sanitary conditions of surrounding atmosphere and environment, and increase the morbidity of the animals' eye, respiratory diseases.

Microorganisms in animal house include pathogenic, conditional pathogenic and non-pathogenic microorganisms. With the development of China's intensive large-scale livestock and poultry husbandry, livestock and poultry animals highly centralized in the animal house. Transmission ways are shortened, and artificial environment also create some new epidemic regularity. Most strong diseases of livestock and poultry spread through the air. Pathogen spread through the air or using the air as medium. Therefore, environmental diseases and air-infectious diseases should be the focus of modern disease prevention and control for the centralization-breeding animals. The non-pathogenic microbial aerosol can aggravate the burden of animal immune organs, or inhibit the immune function, causing the susceptibility of animals in a state of sub-health and sub-clinical symptoms, such as depressed spirits, less exercises, loss of appetite, tearing eyes, more secretions of nose and mouth, low production performance, higher morbidity and elimination rate. Hartmann (1980) concluded that bacteria concentration can still be 20 times higher than normal from $300 \mathrm{~m}$ distance of the cowsheds. Tongjie chai (1997) found that the amount of aerobic bacteria can be up 
to $23.6 \%$ of the shed, and anaerobic bacteria can reach $53.1 \%$ away from $5 \mathrm{~m}$ of the cattle sheds. Air microorganism of the animal house spread to the surrounding environment through the air exchange, and form a high microbes concentration in the surrounding air, leading to animal-origin biological contamination. Tongjie chai studied the air microorganisms in the hen house and the spreading conditions. The results show that microbes in the hen house can spread to the outside environment, and the influence of animal-origin contamination can reach more than $100 \mathrm{~m}$. G.A lber (2003) detected the number of bacteria in the air around the household garbage landfill and explored four different directions of the landfill as sampling points. The results indicated that the number of bacteria decreased gradually from $100 \mathrm{~m}, 200 \mathrm{~m}, 300 \mathrm{~m}, 400 \mathrm{~m}$ to $500 \mathrm{~m}$, but the number of bacteria within $500 \mathrm{~m}$ affected the health of nearby residents to some extent.

The content of aerosol is inversely proportional to the distance of bacteria source. The closer the source of bacteria, the higher the microorganism content of microbial aerosol in the air ( the harm of microbial aerosol). Without timely ventilation and filtration, environmental epidemic will happen with clinical symptoms. The economic loss caused by microbial aerosol disease is much higher than that caused by traditional infectious disease or clinical diagnosis of diseases. Therefore, altering the content of microbial aerosol can greatly improve the animal welfare .

\section{Ground and bedding}

The ground is very important for the animal bodies' comfortable degree, temperature regulation, health and hygiene. For piglets, compared with the strip surface, they prefer solid cement floor, but the cement floor hurt piglets' legs and feet more easily. Therefore, sometimes the choice of the animals is adverse to the need of the body (Broom, 1996). In general, the ground should be required to prevent slippery and injury with clean rest area and good drainage. In the intensive pigs farming, the pigs will be more active, and show more hog and exploratory behavior if given bedding (straw). That's to say, the main function of the straw is to give the pig some stimulation and avoid some bad phenomena (such as biting tail, and fighting). For health reasons, piggery feces and urine must be cleaned in time, and mat grass regularly updated. Otherwise, the harmful gas can cause respiratory diseases, and can lead to abnormal behavior such as biting the tail, allotriophagic. etc.

\section{Lighting}

Simonsen (1990) noticed that Pigs' activities in the fence were just confined to a few hours during the day, morning and afternoon presenting a bimodal distribution. Light rhythm affects pigs' diet, and eating peak are mainly within $2 \mathrm{~h}$ : $1 \mathrm{~h}$ after opening the light and $1 \mathrm{~h}$ before closing the light (Feddesetal1989). Baldwin and Start (1985) put piglets of 8-12 weeks in a light-tight enclosure, and trained them to turn on the power switch with their mouths for 40s light each time.[4] After observing for $24 \mathrm{~h}$, they found that the lamp was only opened for $1.5-2 \mathrm{~h}$, and mainly at the feeding time. On the contrary, if the pigs stayed in the continuous light, they weren't bothered to close the switch for 40s darkness. Therefore, we believe that the continuous light or dark has not too much interference on the pig. The light intensity appears no big effects on the welfare of the pigs. But the pig doesn't like the strong light. Fed in the darkness, they can open the light switch for 40s. And we find that pigs move under the lights about $54 \%$ of the time in $24 \mathrm{~h}$, among which the light intensity is less than 10lux for $63 \%$ of the time. The experience of many farms suggests that dark light is ideal to keep pigs quiet and avoid fighting. This study focuses on the 1002 -week broilers in the Binzhou Bureau of Animal Husbandry to test chickens' reaction under different illumination conditions. The results are as follows: 
Table 3-1 lighting effects on the growth condition of chickens

\begin{tabular}{ll}
\hline Lighting & Chicken conditions $(\mathrm{n}=100)$ \\
\hline Below 5-6 lux & Less activity,breast blisters and increase \\
& in death \\
Below 20 lux & Afraid of frightening \\
Below 50 lux & Less activity, scratches, dust increasing \\
Above 50 lux & Good activity \\
\hline
\end{tabular}

Note: $\mathrm{n}$ on behalf of the sample

The above experimental results show that when the lighting reaches to more than 50 lux, the growth of chickens are in good condition. Therefore, in the process of animal breeding, animals should be given appropriate lighting and suitable environmental conditions, and then animals can play the best growth performance.

\section{Ammonia consistence}

Moisture and high temperature are favorable conditions for the growth of the bacteria, which makes the organics degrade to produce ammonia, and ammonia stimulates the generation of some diseases. Especially in the poultry production, controlling ammonia consistence is an important part of poultry welfare. The degree of ammonia consistence is also associated with poultry' $\mathrm{s}$ higher incidence of contact dermatitis. The severe disease on the claw can lead to limp and leg problems, all of which can make poultry suffer pain and stress.As a result, control of ammonia levels in poultry welfare implementation plays very important roles. Even if we don't consider poultry welfare, more than 50 PPM ammonia consistence will affect the poultry' $s$ growth rate and performance. In high density breeding areas, ammonia levels and behavior factor can attribute to low growth rate. The impact of ammonia on poultry largely depends on the length of exposure time. It should be pointed out that the influence of the high ammonia consistence may be comparable to that of long time exposure under low ammonia consistence.

With the bedding moisture, bacterial activity can produce ammonia. Therefore any indoors factors leading to bedding humidity will affect the ammonia levels. Factors influencing ammonia consistence are: the humidity. The water overflow is the important factors influencing the bedding humidity, which is the reason why now introduce nipple type water fountain. In the hen house, excessive drinking water would happen due to the limit of feeding, causing the bedding moist. the diet. The composition of the diet will also affect the health of the production of ammonia and poultry. About $18 \%$ of the nitrogen content in the feed end up in the form of ammonia diffusion into the air. As a result, the feed with high protein level increase the content of nitrogen in the feces, which will have direct effects on the occurrence of contact dermatitis. Other composition of the diet will have negative influence on bedding quality, or it is the leading cause of drinking more water which leads to wet dung, or make the feces sticky. High levels of sulfur, chloride and potassium in the diet will lead to the increased amount of drinking water. Excessive soybean in the diet can increase the water consumption of poultry birds, because soybean meal is high in potassium. In addition, the high fat content or low digestion fat in the feed can cause excrement containing indigestible fats.which makes the very thick bedding easily stick to poultry 's skin, and the skin becomes more vulnerable to the effects of ammonia. health. Poultry's health condition is one of the considering factors. The deterioration of bedding caused by intestinal disorder lead to outbreaks of diarrhea . In high-density breeding, the problem is particularly serious, because excrement is damp easily. Another consideration is bedding's ability to absorb moisture. The higher ability to retain water, the smaller the influence of breeding density on the quality of the bedding. Bedding in low water levels can significantly reduce ammonia density in the hen house. The thickness of the bedding is also very important, thin bedding is considered to be effective means to reduce inflammation of the skin.

The experiment picked up 50 feather chicken in the Binzhou Bureau of Animal Husbandry, raised them 20 days under different ammonia density, and then studied the productive performance of chicken groups. The results of the experiment are as follows: 
Table 4-1 Effect of ammonia consistence on chicken performance

\begin{tabular}{|c|c|c|}
\hline Ammonia density & $\begin{array}{l}\text { The average } \\
(\mathrm{n}=50)\end{array}$ & $\begin{array}{c}\text { death rate } \\
(\mathrm{n}=50)\end{array}$ \\
\hline Below 5 ppm & $193.4 \mathrm{~g}$ & $4.8 \%$ \\
\hline $5 \sim 10 \mathrm{ppm}$ & $190.8 \mathrm{~g}$ & $8.7 \%$ \\
\hline $10 \sim 20 \mathrm{ppm}$ & $185.4 \mathrm{~g}$ & $15.3 \%$ \\
\hline $20 \sim 30 \mathrm{ppm}$ & $174.3 \mathrm{~g}$ & $25.2 \%$ \\
\hline $40 \sim 50 \mathrm{ppm}$ & $165.3 \mathrm{~g}$ & $31.5 \%$ \\
\hline
\end{tabular}

Note: $\mathrm{n}$ on behalf of the sample

Thus, the lower ammonia consistence, the better the chicken growth, and the higher the productive performance. The best condition is that ammonia consistence is less than 5 PPM .

In order to control the ammonia consistence in a chicken farm, we can do from the following aspects: decrease levels of urea and protein in the diet formula; use nipple type water fountain; consider raising density according to the ventilation of the hen house; keep material with higher moisture ability as bedding; reduce excessive drinking water problems by offering pecking alternatives.

\section{Temperature}

Among the environmental factors affecting the pigs' welfare, temperature is the most important one. Because of the less skin hair, heat preservation ability is poor, heat can be easily sent out. Livestock and poultry can feel the change of environmental temperature sensitively. Either piglets or swine can easily learn to use the nose to open the switch in order to get the heat source. When the temperature falls, the behavior frequency increases; When the temperature rises too high, pigs will turn off the heat source switch, or open the water switch. Studies have shown that different parts of livestock and poultry's body respond to temperatures differently. some parts are sensitive, such as pigs' preoptic area and scrotum. If the temperature is too low, especially for the preoptic area, the pig will increase the frequency of turning on the heat source. Low temperature had a bad effect on livestock and poultry. Breeding livestock and poultry in a cold environment need more calories than raising them in a warm environment. The decrease of temperature has a negative impact on the health of pigs. In the wind, the pig will look for a shelter or crowded together to hold heat. With the temperature decreasing, the frequency of cough, diarrhea and biting tail will increase. In the test of Sallvik and Walberg (1984), pigs can gain heat by pressing the switch of infrared light. When the temperature falls, the action will increase; when the temperature rises too fast, the pigs will open the fan or water cooling equipment. [4,5] But when the temperature rises too fast, the speed of body sending out heat is comparatively lower, then some behavioral responses will happen, such as activity decreases, adjusting the rest position, wallowing in the mud, and drop of feed consumption. There exists an optimum temperature range for pigs, and the baseline of the optimum temperature range is very important for pigs' production. If the temperature is lower than the temperature range, the rate of feed conversion falls. Along with the growth of pigs, optimum temperature will gradually reduce. In general, the optimum temperature for survival of piglets is $34{ }^{\circ} \mathrm{C}$, 4-6 weeks from 25 to $30{ }^{\circ} \mathrm{C}, 8-14$ weeks $25{ }^{\circ} \mathrm{C}$, greater than 14 weeks $20{ }^{\circ} \mathrm{C}$.

\section{Density}

Intensive animal breeding is to make full use of effective space, but meanwhile greatly reduces the individual space of the animals.[6] Normal behavior patterns of animals are confined in the minimum space, which affects animal welfare. Therefore, it is necessary to give adequate consideration for the limiting factors, and to ensure the minimum effective individual space.

In order to study the effects of lowering breeding density on animal performance, the study carried out the following experiment: choose 210 days issa babcock B-380 breeding hens with health parents generation in chicken farm of Binzhou Bureau of Animal Husbandry for the test. In the two experimental groups (E. G.), there are 2 chicken in every little single cage, a total of 60 
chicken occupying $63 \mathrm{~m}^{2}$; the other two control groups (C. G.) are composed of 90 chicken, with 3 chicken in each small single cage, occupying $42 \mathrm{~m}^{2}$. The results of the test are as follows:

Table 6-1 breeding density on the influence of rate (\%)

\begin{tabular}{lcccc}
\hline Subjects & Week 1 & Week 2 & Week3 & average \\
E.G.(n=60) & 81.45 & 86.19 & 88.34 & 85.32 \\
C.G.(n=90) & 83.49 & 85.24 & 80.48 & 83.07 \\
\hline
\end{tabular}

Note: $\mathrm{n}$ on behalf of the sample

Table 6-2 breeding density effect on the breeder eggs qualified rate (\%)

\begin{tabular}{lcccc}
\hline Subjects & Week 1 & Week 2 & Week3 & average \\
E.G.(n=60) & 91.90 & 92.63 & 93.96 & 92.83 \\
C.G.(n=90) & 91.69 & 89.74 & 91.67 & 91.03 \\
\hline
\end{tabular}

Note: $\mathrm{n}$ on behalf of the sample

\begin{tabular}{ccccc} 
Table 6-3 & \multicolumn{5}{c}{ breeding density effect on the broken egg rate (\%) } \\
\hline Subjects & Week 1 & Week 2 & Week3 & average \\
E.G.(n=60) & 2.52 & 1.12 & 1.62 & 1.75 \\
C.G.(n=90) & 2.19 & 4.48 & 2.37 & 3.01 \\
\hline
\end{tabular}

Note: $\mathrm{n}$ on behalf of the sample

The above results show that the lower density can significantly improve the rate of laying hens, greatly improve the quality of egg production, and reduce the rate of broken eggs. Living environment directly affect the health of the chicken and endocrine physiology. High breeding density not only causes the increase of environment dust, microorganisms, and the concentration of harmful gas, and chickens are often in a state of stress due to the narrow, crowded living environment space, limited movement, feeding and drink area. Any stress reaction will make adrenal cortical hormone secretion increase, the adrenal cortical hormone for poultry reproductive hormones can inhibit the synthesis and secretion, and stress can also reduce the poultry immune and reproduction function. In this test, the performance of chickens laying eggs had been improved significantly by reducing the chicken breeding density, increasing the chicken activity space, and relieving the negative effects of environmental stress on chicken. Therefore, in the process of animal production, the breeding density need to be arranged appropriately so as to provide a better living environment.

Animal welfare is a new topic. Paying attention to animal welfare is not only the inevitable trend for the sustainable development of animal husbandry in our country, but also a more important issue for human survival. Since "to protect animals is to protect human ourselves", endangering animals are actually endangering human's survival. To improve animal welfare in the intensive farm, we should start from improving the environment of raising animals, thus improve the quality of animals and animal products.

\section{Acknowledgements}

College and universities in Shandong province science and technology plan projects,item number:J15LF54 


\section{References}

[1] Weary D,Fraser D. Partial tooth-clippuag of suckluag pigs:effects onneonatal competition and facial injuries J.Applied Animal Be-haviour Science,1999,65:21-27.

[2] Fraser A F,et a1.Farm anunal behaviour and welfare MJ.London:Balliere Tuadall 1990.

[3] Beanie V E, Waetherup R N. Moss B W .The effect of feed restriction prior to slaughter on performance and meat quality of pigs. British Society of Animal Science. 1999. P11.

[4] Sielly J,et a1.Castration at 3 days of age temporarily slows growth of pigs.Swuie Health and Productoion, 1999(7):151-153.

[5] Lopez -Senano M,et al.Genetic conelations of growth,backfat thickness and exterior with stayability ua large white and landrace sows,J.Livestock Production Science,2000,64(2/3):121131.

[6] Beattie V E, Walker N, Sneddon I A. An investigation of the effect of environmental enrichment and space allowance on the behaviour and production of growing pigs. Applied Animal Behaviour Science, 1996. 48: 151-158. 